\title{
A simple image intensifying system for Berg-Barrett topography
}

\author{
T. Vreeland,Jr. and S. S. Lau \\ W. M. Keck Laboratory of Engineering Materials, California Institute of Technology, Pasadena, California 91109 \\ (Received 15 April 1974; and in final form, 2 May 1974)

\begin{abstract}
A simple imaging system to facilitate crystal orientation with respect to the $\mathrm{x}$-ray beam for Berg-Barrett topography has been constructed. This system consists of an image intensifier tube with an x-ray phosphor deposited on its fiber-optic input plate and means to manipulate and indicate the crystal orientation. Applications of the system to studies of both crystalline and biological samples are given.
\end{abstract}

\section{INTRODUCTION}

X-ray topographic methods have been employed in a variety of studies of crystalline materials (see review by Armstrong and $\mathrm{Wu}^{1}$ ). In both transmission and reflection topography, the specimen is oriented for Bragg diffraction from a known set of crystallographic planes. Bragg reflections are usually detected by a radiation counter, or by direct viewing of the reflection on a fluorescent screen. A few investigators have employed viewing of the intensified image formed on a fluorescent screen (Lang and Reifsnider, ${ }^{2}$ Green $^{3}$ ) and others have used $\mathrm{x}$-ray video systems $\left(\right.$ Green $\left.^{3}\right)$.

Direct viewing of the image on a fluorescent screen without electronic intensification is difficult because of the low x-ray intensity. Optimum adjustment of the crystal orientation can only be approximated in this manner and must be checked by the use of film. The image intensification system described in this paper for reflection topography provides sufficient luminous gain that complete darkness and dark adapted vision are not required as they were for the system used previously (Turner, Vreeland, and Pope) $)^{4}$. An improved construction of the Berg-Barrett camera has been reported by Liang and Pope. ${ }^{5}$ Their camera is totally enclosed to decrease radiation exposure to the experimenter, but this enclosure restricts the placement and observation of the fluorescent screen. The Berg-Barrett camera described here permits the fluorescent screen to be placed close to the specimen (to increase resolution) and provides ample radiation shielding for the experimenter.

\section{THE IMAGE TUBE}

An RCA type 4549 tube with a $40 \mathrm{~mm}$ diam input face is used. This is a three-stage electrostatic focus image intensifier with a luminous gain of about $75000 \times$ and a maximum center resolution of $40 \mathrm{lp} / \mathrm{mm}$. The tube operates from a $6.75 \mathrm{~V}$ dc power source and generates $45 \mathrm{kV}$ internally. The tube is supplied with a current limiting circuit, and for use with the input end grounded. It would be desirable to have the viewing end of the tube grounded, but this would require the input end to be at $-45 \mathrm{kV}$ and prevent its placement close to the (grounded) specimen for optimum resolution.
An x-ray phosphor can be deposited directly onto the input plate of the image tube or onto a well-polished fiber-optic plate which is coupled to the input plate of the tube with silicon grease or optical cement. Deposition is achieved by either a settling process (Stone ${ }^{6}$ ) or an electrophoretic process (McGee, Airey, and Aslam ${ }^{7}$ ). A settled coating was found to be somewhat easier to apply. We are currently using a General Electric 118-2-19 phosphor ( $\mathrm{ZnCdS}, \mathrm{P}-20$, with a particle size of 3-4 $\mu$ ). The fine particles of phosphor were separated by flotation and a coating of a few microns in thickness $\left(\sim 1 \mathrm{mg} / \mathrm{cm}^{2}\right)$ was deposited by the settling process. This coating is sufficiently thin so that it does not degrade the resolution of the system. While the phosphor coating thickness may be optimized (to maximize luminous output) for a given $\mathrm{x}$-ray wave length, the $1 \mathrm{mg} / \mathrm{cm}^{2}$ is a good compromise for the commonly used radiations $\left(\mathrm{Cr} \mathrm{K}_{\alpha}\right.$, Co $\left.\mathrm{K}_{\alpha}\right) .40 \mu$ gold dots flashed onto a zinc specimen with basal surface orientation can be resolved from an $x$-ray topographic image taken from the output plate of the present system.

The x-ray phosphor on the input end of the image tube is covered by a thin opaque plastic film which prevents room light from exciting the phosphor. Metal foil x-ray filters are taped over the plastic film when they are needed to attenuate either $\mathrm{x}$-ray fluorescence from the crystal or unwanted Bragg reflections due to characteristic $\mathrm{K}_{\beta}$ radiation.

The tube is clamped in a horizontal position so that it projects through a metal plate which serves as a radiation

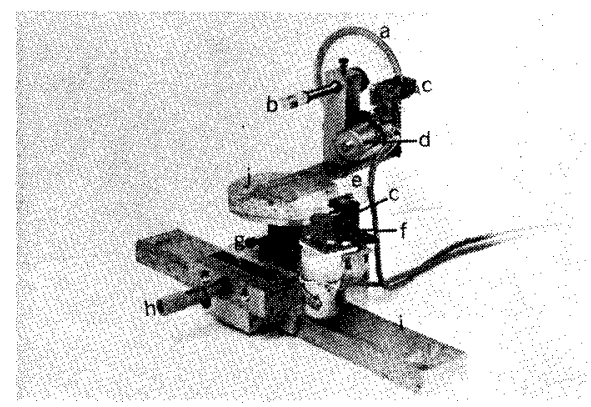

FIG. 1. Photograph of the camera with the drives in place. a- $-360^{\circ}$ protractor for roll angle; $b$-specimen; $c$-optoelectronic system; $\mathrm{d}-\mathrm{dc}$ gearmotor; $\mathrm{e}-180^{\circ}$ protractor for Bragg angle; $\mathrm{f}$ - friction drive; $\mathrm{g}-$ vertical adjustment; $\mathrm{h}$-manual micrometer drive; $\mathrm{i}-\mathrm{x}$-ray track; and $j-$ circular table. 


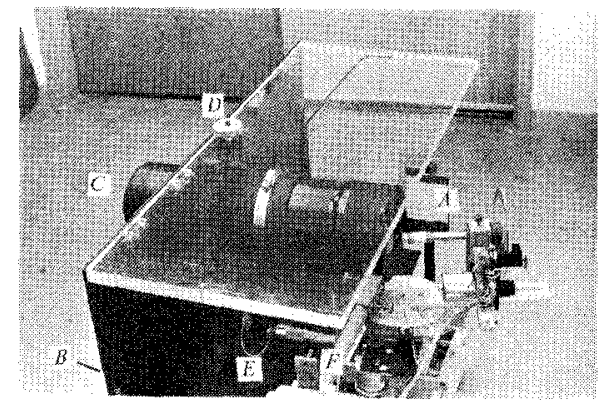

FG. 2. Imaging system with the image tube in place. A-x-ray beam stop with fluorescent screen; $\mathrm{B}$-image tube assembly; Cviewingr end of the image tube; I)-vertical adjustment for the image tube; E-flexible cable for micrometer drive; and $\mathrm{F}-\mathrm{x}$-ray slit collimator tube.

shield. This shield, and the tube itself protect the experimenter from radiation emanating from the $x$-ray tube and the specimen. Adjustments are provided for both the height of the image tube and its projection through the plate.

\section{CRYSTAL MANIPULATIONS}

The camera parts described in Turner et al. ${ }^{4}$ were used. These parts provide for translation perpendicular to the $\mathrm{x}$-ray track (manual micrometer drive), vertical adjustment of the crystal (perpendicular to the $x$-ray track), Bragg angle adjustment (rotation of a $10 \mathrm{~cm}$ circular table about a vertical axis), and roll angle about the normal to the crystal face.

A flexible coupling attached to the micrometer drive and passing through the metal plate of the image tube mount permits translation adjustments to be made. $A 15 \mathrm{~cm}$, $180^{\circ}$ protractor was attached to the circular table. Direct current gearmotors provide a friction drive for the protractors on the circular table and on the roll angle adjustment. An optoelectronic system is incorporated in each motor mount assembly to generate signals which indicate angular position. When rotation occurs, the protractor divisions (black lines on a clear plastic) are counted by this system. Bragg angle and roll angle adjustments are made, with control on speed and direction, and displayed

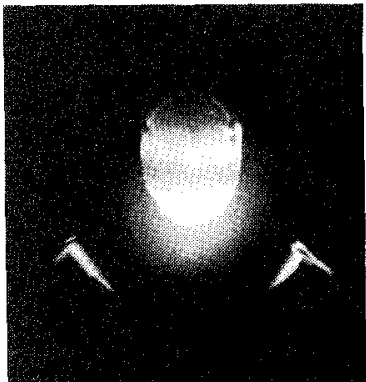

(a)

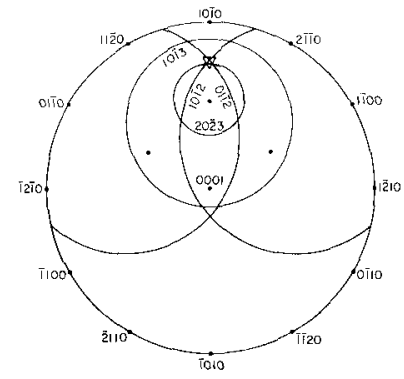

(b)
Fig. 3. (a) Symmetry pattern of a zinc crystal with basal surface orientation showing three reflecting conditions simultaneously. (b) The geometry used to obtain the topograph of Fig. 3(a) is shown as a triangle in the shaded area of the reflection locus plot. Zinc (0001) surface, $C_{0} K_{\alpha}$ radiation. Due to the finite size of both $\mathrm{x}$-ray source and crystal surface area, three reflections are obtained although the three reflecting loci do not intersect at a common point. Fluorescence from the specimen causes the bright haze in the center of the picture.

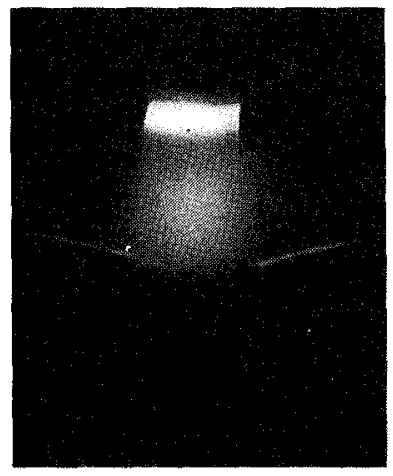

(a)

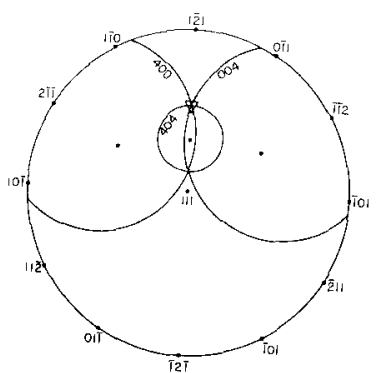

(b)
Fic. 4. (a) Symmetry pattern of a silicon crystal with (111) orientation satisfying three reflecting conditions simultaneously. (b) The geometry used to obtain the topograph of Iig. $4(a)$ is shown as a triangle in the shaded area of the reflection locus plot. Silicon (111) surface, Co $\mathrm{K}_{\alpha}$ radiation.

on a hand-held control box (Bragg angle display reads $0.0^{\circ}-99.5^{\circ}$ in $0.5^{\circ}$ increments and roll angle display reads $0^{\circ}-360^{\circ}$ in $1^{\circ}$ increments). A photograph of the camera with the drives in place is shown in Fig. 1. Figure 2 shows the system with the image tube in place.

\section{APPLICATIONS}

\section{A. Determination of Crystal Orientation with Respect to the X-ray Beam}

In order to align the crystal for a specific Bragg reflection, it is necessary to establish the crystal orientation with respect to the incident beam. For example, if the zero layer (1013) reflection from a zinc specimen with basal surface orientation is desired, it is best to select an incident beam direction to satisfy the $(20 \overline{2} 3),(01 \overline{1} 2)$ and (1012) reflecting conditions simultaneously as indicated by the shaded area on the locus plot in Fig. 3(b). Once the symmetry pattern is identified on the image tube [shown on Fig. 3(a)] the zero layer of the (1013) reflection or any other possible reflections can be obtained by adjusting the crystal (Bragg angle and roll angle adjustment) to the required orientation according to the reflection locus plot. All crystallographic directions on the specimen surface can also be determined by first establishing the location of the symmetry pattern. Another example is shown in Fig. 4(a) and (b) where the incident beam satisfies the (404), (400), and (004) reflections simultaneously for a (111)-oriented

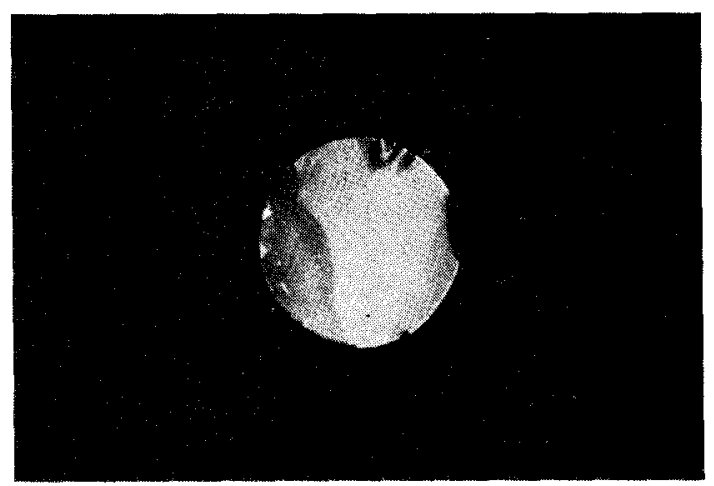

FIG. 5. Topograph of a zinc crystal with (0001) surface showing substructure and damage. Zero layer of (1013) reflection. 


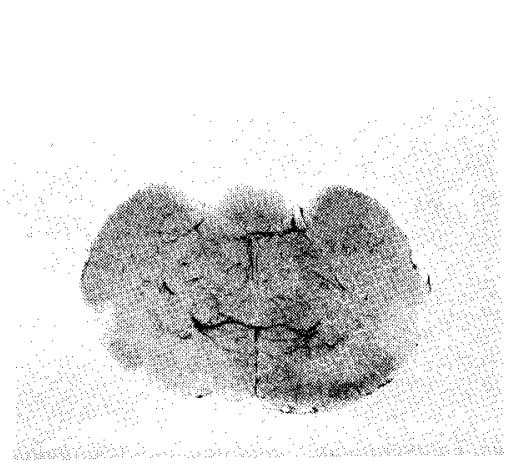

(a)

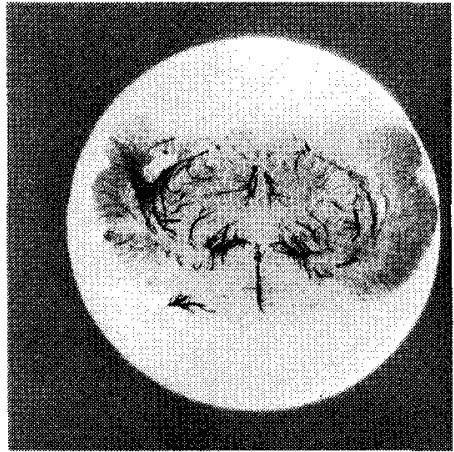

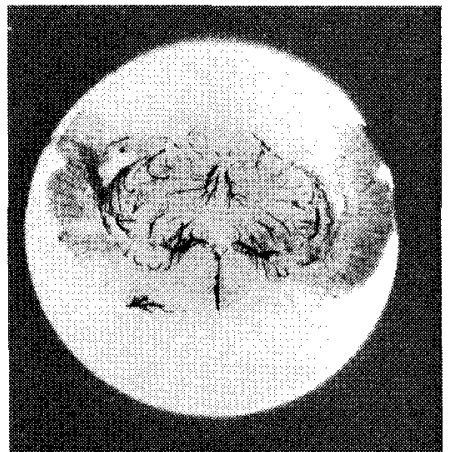

(b)

FIG. 6. (a) Image of a rat brain section recorded by a commercial unit (Faxatron, manufactured by the Field Emission Co.). 1.5 cm in width, $1 \mathrm{~mm}$ thick. (b) Stereo pair of images of a similar rat brain section recorded with the present system.

silicon crystal. It should be noted that the $(01 \overline{1} 2)$ and (1012) reflections for zinc and the (400) and (004) reflections for silicon are weak and narrow, and are difficult to observe without image intensification.

\section{B. Survey of Possible Bragg Reflection for Topography}

An optimal Bragg reflection should have a strong reflecting intensity and a large reflecting area. The present system allows a quick survey of all possible Bragg reflections and the determination of the optimal reflection for topography.

\section{Survey of Crystal Quality}

Substructure, scratch and handling damage in the specimen are easily identified by observation of the intensified image. Figure 5 shows an example of an image obtained from a poor quality zinc crystal. Both damaged areas and subgrains are clearly revealed. The dimensions of the subgrains and damaged areas can also be estimated.

\section{Determination of Diffracting Area}

It is often necessary to determine which portion of the crystal is diffracting, as in the case where different reflections from the same area are to be obtained. This simple imaging system is very useful for adjusting the specimen so that the area of interest is strongly diffracting.

\section{E. Biological Applications}

Biological samples have been examined using this imaging system. Sections of rat brain with a barium compound injected into the blood vessels were examined with $\mathrm{Cu} \mathrm{K}_{\alpha}$ radiation. The samples are typically $1 \mathrm{~mm}$ thick. The sample was placed in the direct $\mathrm{x}$-ray beam and the imaging system was placed behind and in contact with the rat brain section. Transmission images of the sample observable on the output end of the image tube were recorded on photographic films. Figure 6(a) shows a rat brain section recorded by a commercial unit (Faxatron manufactured by the Field Emission Company, $\mathrm{W}$-radiation, $25 \mathrm{kV}$, $3 \mathrm{~mA}, \sim 8 \mathrm{~min}$ exposure time). Figure $6(\mathrm{~b})$ shows a similar rat brain section recorded in a stereo pair with the present system (copper radiation, $8 \mathrm{kV}, 1 \mathrm{~mA}, 15 \mathrm{sec}$ exposure time). We have found that the present system produced a rat brain image with better resolved vessels with much shorter exposure time. When $W$ radiation is used with the present system quantum noise is significantly reduced with an operating voltage of $15 \mathrm{kV}$ and above and the required exposure time is reduced to a fraction of a second.

\section{ACKNOWLEDGMENT}

We would like to thank Dr. Douglas C. Mohr for his helpful assistance in the preparation of phosphor screens.

${ }^{1} \mathrm{R}$. W. Armstrong and C. Cm. Wu, Microstructural Analysis: Tools and Techniques, edited by J. L. McCall and W. M. Mueller,

(Plenum, N.Y., 1973). Also see "X-ray Diffraction Microscopy," by R. W. Armstrong and C. Cm. Wu, E.M.G. Report No. CXXI, University of Maryland, Center of Materials Research, College Park, Maryland.

${ }^{2}$ A. R. Lang and K. Reifsnider, Appl. Phys. Let. 15, 258 (1969).

${ }^{3} \mathrm{R}$. E. Green, Jr., Advances in X-ray Analysis, edited by C. S. Barrett, Vol. 14, p. 311 .

${ }^{4}$ A. P. L. Turner, T. Vreeland, Jr., and D. P. Pope, Acta Cryst., A24, 452 (1968).

5S. L. Liang and D. P. Pope, Rev. Sci. Instrum. 44, 8, 956 (1973).

${ }^{6} \mathrm{H}$. D. Stone, Advances in Electronic Imaging and Electron Physics, Vol. $22 \mathrm{~A}$, p. 571

7J. D. McGee, R. E. Airey, and M. Aslam, Advances in Electronic Imaging and Electron Devices, Vol. 22A, p. 571. 